University of Wollongong

Research Online

Faculty of Social Sciences - Papers (Archive) Faculty of Arts, Social Sciences \& Humanities

2014

Early in-session cognitive-emotional problem-solving predicts 12-month outcomes in depression with personality disorder

Kye L. McCarthy

University of Wollongong, klm825@uowmail.edu.au

Erhardt Mergenthaler

University of Ulm, erhard.mergenthaler@uni-ulm.de

Brin F. S Grenyer

University of Wollongong, grenyer@uow.edu.au

Follow this and additional works at: https://ro.uow.edu.au/sspapers

Part of the Education Commons, and the Social and Behavioral Sciences Commons

Research Online is the open access institutional repository for the University of Wollongong. For further information contact the UOW Library: research-pubs@uow.edu.au 


\title{
Early in-session cognitive-emotional problem-solving predicts 12-month outcomes in depression with personality disorder
}

\author{
Abstract \\ Therapist-patient verbalizations reveal complex cognitive-emotional linguistic data. How these variables \\ contribute to change requires further research. Emotional-cognitive text analysis using the Ulm cycles \\ model software was applied to transcripts of the third session of psychotherapy for 20 patients with \\ depression and personality disorder. Results showed that connecting cycle sequences of problem-solving \\ in the third hour predicted 12-month clinical outcomes. Therapist-patient dyads most improved spent \\ significantly more time early in session in connecting cycles, whilst the least improved moved into \\ connecting cycles late in session. For this particular sample, it was clear that positive emotional problem- \\ solving in therapy was beneficial.

\section{Keywords} \\ solving, problem, emotional, cognitive, disorder, session, personality, early, depression, outcomes, month, \\ 12 , predicts \\ Disciplines \\ Education | Social and Behavioral Sciences

\section{Publication Details} \\ McCarthy, K. L., Mergenthaler, E. \& Grenyer, B. F. S. (2014). Early in-session cognitive-emotional problem- \\ solving predicts 12-month outcomes in depression with personality disorder. Psychotherapy Research, 24 \\ (1), 103-115.
}


McCarthy, K.L., Merganthaler, E., Grenyer, B.F.S. (2014). Early in-session cognitive-emotional problem-solving predicts twelve-month outcomes in depression with personality disorder. Psychotherapy Research, 24 (1), 103-115. DOI: 10.1080/10503307.2013.826834

This version revised 25/52013, accepted 16 July 2013

Running head: IN-SESSION COGNITIVE-EMOTIONAL PROCESS AND OUTCOME

Early in-session cognitive-emotional problem-solving predicts twelve-month outcomes in depression with personality disorder

Kye L. McCarthy ${ }^{1}$, Erhard Mergenthaler ${ }^{2}$ and ${ }^{*}$ Brin F. S. Grenyer ${ }^{1}$

${ }^{1}$ School of Psychology \& Illawarra Health and Medical Research Institute, University of Wollongong, NSW, Australia

${ }^{2}$ Clinic for Psychosomatic Medicine and Psychotherapy, University of Ulm

* Correspondence concerning this article should be addressed to Professor Brin F. S. Grenyer, PhD, Department of Psychology, University of Wollongong, NSW, 2522, Australia. Phone: +61 242213474 Fax: +61 242683591 Email: grenyer@uow.edu.au 


\begin{abstract}
Therapist-patient verbalisations reveal complex cognitive-emotional linguistic data. How these variables contribute to change requires further research. Emotional-cognitive text analysis using the Ulm cycles model software was applied to transcripts of the third session of psychotherapy for 20 patients with depression and personality disorder. Results showed that connecting cycle sequences of problem solving in the third hour predicted 12-month clinical outcomes. Therapistpatient dyads most improved spent significantly more time early in session in connecting cycles, whilst least improved moved into connecting cycles late in session. For this particular sample, it was clear that positive emotional problem solving in therapy was beneficial.
\end{abstract}

Keywords: Process-outcome, linguistic analysis, psychotherapy, depression, personality disorders 


\section{Introduction}

There has been renewed interest in therapist behaviours and qualities that promote a facilitative therapy relationship (Norcross \& Wampold, 2011). Psychotherapy has consistently been found to be effective (Luborsky, Singer, \& Luborsky, 1975; Wampold, 2000), yet how it works in terms of in-therapy processes and sequences of change requires research (Elliott, 2010). This is a critical area of inquiry in order to continually develop effective therapeutic interventions (Ablon, Levy, \& Katzenstein, 2006; Lambert, 2007). The therapeutic alliance between patient and therapist has long been recognised as a psychotherapeutic variable related to treatment outcome (Horvath, Del Re, Flückiger, \& Symonds, 2011). However, the recent task force on evidence-based therapy relationships highlighted that few studies have explored the process of how the therapist-patient relationship facilitates improvement in therapy, with few methodologies capable of disentangling complex associations between patient, therapist, their relationship, and outcome (Norcross \& Wampold, 2011).

\section{Therapist and Patient Factors in Psychotherapy Process}

Research has long investigated therapist factors and techniques related to improvement in psychotherapy, with therapist skill and capacity to establish a therapeutic alliance showing robust relationships to positive therapeutic outcomes (Blatt, Sanislow, Zuroff, \& Pilkonis, 1996; Luborsky, McLellan, Woody, O’Brien, \& Auerbach, 1985; Orlinsky, Grawe, \& Parks, 1994). Recent research suggests that therapist contribution to the alliance is actually more important to the correlation between alliance and therapy outcome than is the patient contribution- therapists who formed better alliances had better outcomes (Baldwin, Wampold, \& Imel, 2007; Del Re, Flückiger, Horvath, Symonds, \& Wampold, 2012; Dinger, Strack, Leichsenring, Wilmers, \& Schauenburg, 2008). Whilst therapist techniques have been linked to patient expression of affect 
and better alliance in therapy (Ackerman \& Hilsenroth, 2003; Town, Hardy, McCullough, \& Stride, 2012), there have been few studies examining the interior nature of successful and unsuccessful sessions at the level of the therapist-patient dialogue. Recent literature has begun to examine therapist-patient discourse to identify therapist and patient contributions to significant change processes within therapy (Levitt \& Piazza-Bonin, 2011). In particular, Valdés et al. (2010) found that within change moments patients brought up an number of different emotions and therapists explored these emotions rather than introducing new ones.

Evidence suggests that successful therapy is recognisable from early sessions (Comninos \& Grenyer, 2007). Studies of brief cognitive therapies for depression have found that patients least improved by session 3-4, were also least improved at long-term follow-ups of 12-18 months (Fennell \& Teasdale, 1987; Gilboa-Schechtman \& Shahar, 2006). It is less clear what makes early sessions so useful to some patients, as such studies have not further characterised the interior of the early session for early improved patients or their therapists. One possible line of inquiry is the relationship between early session language use by the therapist and patient, and outcome. One study found that in session 3 of 14 sessions of therapy, therapist statements that were subtly hostile and controlling correlated with self-blaming statements of the patient, and were associated with poorer outcome (Henry, Schacht, \& Strupp, 1990).

\section{Psychotherapy for Major Depression and Personality Disorder}

Both major depression and personality disorders are highly prevalent, recurrent and persistent, often comorbid, and are linked to significant functional impairment and morbidity (Bromet et al., 2011; Kessler et al., 2005; Leichsenring, Leibing, Kruse, New, \& Leweke, 2011; Lin et al., 1998). Personality disorders have been increasingly investigated as a factor in the outcome of major depressive disorder, with recent findings indicating that a comorbid diagnosis of 
personality disorder elevated the risk of persistence of major depressive symptomatology (Levenson, Wallace, Fournier, Rucci, \& Frank, 2012; Newton-Howes, Tyrer, \& Johnson, 2006; Skodol et al., 2011). Psychotherapy is considered primary treatment for both major depression and personality disorders (National Institute for Health and Clinical Excellence, 2009a, 2009b). However, psychotherapy with these patients can be highly challenging due to chronic patterns of self-defeating behaviours, inability to form and maintain interpersonal relationships, and their tendency to enact maladaptive relationship patterns in their relationship with their therapist (Bourke \& Grenyer, 2010; Hollon, Thase, \& Markowitz, 2002; Skodol et al., 2002; Zanarini, 2009). Hence, there seems to be a heightened need to investigate therapeutic change processes, particularly in terms of the therapist-patient relationship, for patients with such chronic comorbid diagnoses.

\section{Emotion and Cognition in Psychotherapy}

Psychotherapy literature has long discussed the likely relevance of emotion and cognitive constructs. Recent functional neuroimaging studies have found that therapy outcome is associated with significant metabolic changes in limbic and cortical regions (Benelli et al., 2012; Goldapple et al., 2004; Linden, 2006), and specifically, that long-term therapy for depression induces neurobiological changes in neural pathways implicated in emotional reactivity and control (Buchheim et al., 2012). There have also been empirical attempts to study the benefits of therapeutic processes which lead to affective and cognitive integration. Patient mastery of emotional self-control and cognitive self-understanding has been found to be related to improvement in symptoms (Grenyer \& Luborsky, 1996). A relationship has also been found between the therapist's emotional language within therapy and outcome for the patient, particularly when therapists named more emotions in sessions (Hölzer, Pokorny, Kächele, \& 
Luborsky, 1997). A number of studies have particularly investigated positive emotion and its relationship to cognition. These have found a relationship between positive emotion and cognitive abilities of the patient, that is, positive emotions improve creative problem solving skills by increasing the tendency to combine and relate material in new ways (Frederickson, 1998, 2001; Isen, Daubman, \& Nowicki, 1987; Links, Bergmans, \& Cook, 2003).

\section{The Therapeutic Cycles Model}

Linguistic methods have been used to measure emotion and cognition expressed through dialogue within therapy. Linguistic processing technologies are an innovative window into the interactions between therapist and patient, and provide an opportunity to investigate verbal processes in relation to the outcome of therapy. Reviews of computer-assisted linguistic research approaches can be found elsewhere (Mergenthaler \& Bucci, 1999; Pennebaker, Mehl, \& Niederhoffer, 2003). The Therapeutic Cycles Model (TCM) is a computer-assisted text analysis investigating psychotherapeutic processes at the level of the therapist and patient emotionalcognitive dialogue (Mergenthaler, 1996). The TCM may also been used to analyse the dialogue of therapist and patient individually (McCarthy, Mergenthaler, Schneider, \& Grenyer, 2011), demonstrating the usefulness of the TCM as a tool to separate therapeutic processes of patient and therapist.

The TCM measures the frequency of marker words for emotional tone (affective language tapping into emotion), abstraction (conceptual language tapping into cognition), and narrative style (storytelling marker words that are neither emotion nor abstraction) (Mergenthaler, 2008). Research has found differences in overall emotional and cognitive language use in session based on patient outcome, particularly that emotion and cognition is higher in sessions of improved patients (Mergenthaler, 1996). The TCM also measures four conditions, or emotion-abstraction 
patterns. Each indicates a phase of therapeutic discourse (Mergenthaler, 1996, 2008). Relaxing is where emotional tone and abstraction are below the mean; discourse is regenerative and descriptive. Reflecting occurs when emotional tone is below and abstraction above the mean; a phase of intellectual cognitive processing. Experiencing is identified where emotional tone is above and abstraction below the mean; emotions are experienced. Connecting is where emotional tone and abstraction are above the mean; there is emotional access to conflictive themes, theorised as necessary for change to occur. The critical connecting pattern has been associated with treatment success across a number of theoretical orientations and across diagnostic groups (Mergenthaler, 2008). However, the relationship between relaxing, reflecting and experiencing patterns in sessions, and treatment outcome, is unclear (Mergenthaler, 2008).

The TCM identifies significant events conducive to therapeutic improvement by marking them as connecting cycles. Connecting cycles are presumed significant events that can be identified as a relaxing-connecting-relaxing sequence of language, and indicate where emotion and cognition are elevated and connected for a problem solving phase to occur (Mergenthaler, 2008). A great deal of research has now shown connecting cycles to be consistently related to therapeutic success, and also to a number of psychological and therapeutic processes (Buchheim \& Mergenthaler, 2000; Gelo \& Mergenthaler, 2012; Lepper \& Mergenthaler, 2005, 2007, 2008; Villmann, Liebers, Bergmann, Gumz, \& Geyer, 2008; Walter et al., 2010). A “connecting cycle” is a key moment in therapy. It begins and ends with a relaxing pattern, and must contain a connecting pattern (when emotion language and abstraction language are both high). Thus, connecting cycles are significant events of heightened reflection and emotional engagement in the material. Shift events indicate where a connecting phase is to begin, and thus an insight or change is to follow, identified where positive emotion increases above the mean after a negative 
period (Mergenthaler, 2008). According to TCM literature, positive emotion words are emotional tone words categorised as representing positive emotions, and are considered to "broaden-andbuild” within therapy, that is, initiate a problem solving experience. Negative emotions, similarly, are emotional tone words categorised as negative emotions, and are considered to “deepen-and-provide” within therapy, present where problematic material is being presented (Mergenthaler, 2008).

The present study seeks to investigate individual therapist and patient processes at the indepth level of their dialogue across a session. Specifically, we will examine how therapist-patient emotional and cognitive dialogue influences therapeutic change for the patient, using the TCM. We are specifically interested in psychotherapy processes with patients with comorbid diagnoses of major depression and personality disorder due to the well documented difficult nature of their psychotherapy. A new variant of the TCM method - separating therapist and patient narrative events - was developed here in order to identify the individual roles of each speaker within the change process.

The TCM has only been used in one study to identify change processes in early sessions (Mergenthaler, 1996), and has thus far not investigated the interior sequence of early session language in relation to long-term outcome. Research reviewed suggested not only that long-term change can be recognised early in therapy, but that differences in the interaction between therapist and patients can also be recognised as early as session 3, through the type of language they use (Fennell \& Teasdale, 1987; Gilboa-Schechtman \& Shahar, 2006; Henry, et al., 1990). Few studies have investigated the nature of early sessions, and the processes in early session that are useful to patients. To examine this further, session 3 was chosen for investigation in this study as it is a very early session, and follows after the initial relationship establishment and goal 
setting that occurs in sessions 1 and 2. Therefore, we specifically aimed to investigate group differences between therapists and most and least improved patients (assessed at 12-month follow-up) in their use of emotional-cognitive language across the time of session 3. Due to a noted lack of research into therapeutic processes throughout the course of a session, we particularly focused on comparing language during early (minutes 0-20), middle (minutes 21-40) and end (minutes 41-60) segments of session, in order to characterise the interior sequence of the session. We planned to examine differences across the time of the session in number of connecting cycles, emotion-abstraction patterns and shift events. We also examined whether therapist-patient emotional and cognitive dialogue differed between most and least improved patients during the entirety of session 3. We planned to examine differences between groups on all variables: connecting cycles, emotion-abstraction patterns, emotional tone and valence, abstraction, narrative style and shift events.

Based on previous research utilising the TCM, we particularly expected that in session 3 the most improved group would pass more connecting cycles than would least improved; and, the proportion of time spent in emotion-abstraction patterns (relaxing, reflecting, experiencing, connecting) would differ between most and least improved groups. Further, we hypothesized that there would be a difference in the relative frequencies of emotional tone, abstraction and narrative style between most and least improved groups; and, those most improved would have higher relative frequencies of positive emotional tone and lower relative frequencies of negative emotional tone.

\section{Method}




\section{Data Source}

Participants were 20 patients undergoing psychotherapy at a university health service clinic, with DSM-IV diagnoses (American Psychiatric Association, 1994) of major depression and personality disorder (Cluster A: 2, Cluster B: 6, Cluster C: 12, Not otherwise specified: 8; see Table 1 for sample characteristics). Personality disorder was a consistent diagnosis for all clients, and all met the severity criterion for clinical significance of personality disorder in that the disorder interfered in more than one important part of their life (e.g. work, relationships). The distribution of clusters between the two groups was approximately equal (e.g. the least improved had one cluster $\mathrm{A}$, four cluster $\mathrm{B}$, three cluster $\mathrm{C}$ and three NOS, with one patient having both a cluster $\mathrm{A}$ and $\mathrm{C}$ diagnosis). In relation to the subtypes within clusters, both with a Cluster A disorder were of the Paranoid subtype $(\mathrm{N}=2)$, most with a Cluster $\mathrm{B}$ diagnosis were of the Borderline subtype ( $\mathrm{N}=4)$, and, most in Cluster $\mathrm{C}$ were Avoidant $(\mathrm{N}=5)$ or Dependent $(\mathrm{N}=4)$. All participants gave written informed consent to participate in this research following Institutional Review Board approval.

\section{Participant Selection}

The 20 patients included in this study were carefully selected as a sub-sample of the clinic's clients, and are representative of the continuum of good-poor outcome at 12-month follow-up from the clinic case-mix. A number of criteria were considered when selecting patients according to the aims of this study as follows. Clients of the clinic are either referred by another health professional, or self-referred. To ensure that all participants had the same dosage of treatment, participants were excluded if they did not complete the full course of treatment of 16 sessions, and if they had symptom data missing at intake, termination or follow-up. Participants were also

excluded if they commenced treatment with a Beck Depression Inventory (BDI) (Beck, Ward, 
Mendelson, Mock, \& Erbaugh, 1961) score of $\leq 15$, as low scores at follow-up therefore would not be representative of a great level of improvement. The 20 patients selected had consistent diagnoses of major depression and personality disorder in accordance with the aim of the study (American Psychiatric Association, 1994). Patients were independently assessed with a structured clinical interview (SCID-I and SCID-II) (First, Gibbon, Spitzer, Williams, \& Benjamin, 1997; First, Spitzer, Gibbon, \& Williams, 1996) by an experienced, trained clinician who had achieved excellent reliability on these measures. The following comorbid diagnoses were excluded to ensure homogeneity of diagnoses and thus of symptoms targeted for treatment: current substance dependence, schizophrenia or other psychotic disorder, bipolar disorder, obsessive-compulsive disorder, eating disorder, organic brain disorder or serious medical conditions (e.g. cancer).

According to the aim of the study to investigate therapeutic processes according to patient follow-up outcome, the sample of 20 was also selected to comprise 10 patients who were considered to have a "most improved" outcome and 10 patients considered to have a "least improved” outcome at 12-month follow-up. These two groups of patients were therefore carefully matched for intake diagnoses and measures of symptomatology, as well as demographic variables, but were purposefully mismatched with opposing outcomes at 12-month follow-up. The two equal samples of 10 patients were selected as most and least improved using the recommended cutoff of 16 on the BDI at 12-month follow-up (Cohen, Norris, Acquaviva, Peterson, \& Kimmel, 2007; Matthey, Barnett, Ungerer, \& Waters, 2000; Pinto \& Francis, 1993; Taylor \& Klein, 1989). It has been suggested that $\mathrm{BDI} \geq 17$ is most closely associated with depressive states therefore helping to identify those in the study who had not recovered (Kendall, Hollon, Beck, Hammen, \& Ingram, 1987). Each patient's BDI and Global Assessment of Functioning (GAF) were measured at intake, termination and 12-month follow-up. The BDI is a 
self-report measure of the intensity of 21 depressive symptoms and attitudes. The psychometric properties of the BDI have been well researched, with internal consistency reported as a mean coefficient alpha of .86 for psychiatric populations (Beck, Steer, \& Garbin, 1988). The GAF is a rating scale (0-100) of psychological, social and occupational functioning (American Psychiatric Association, 1994). Studies have found the GAF to have good inter-rater reliability and concurrent validity (Startup, Jackson, \& Bendix, 2002). The 10 most improved patients had mean intake and 12-month scores on the BDI of $26.30(S D=7.75)$ and $6.40(S D=4.38$; $\min =1$, $\max =16)$ respectively, along with mean intake and 12-month GAF scores of $56.2(S D=8.30)$ and 77.50 $(S D=6.35)$. The 10 least improved patients had mean intake and 12-month scores on the BDI of $29.70(S D=5.25)$ and $21.88(S D=4.34, \min =17, \max =28)$ respectively, along with mean intake and 12-month GAF scores of $49.30 \quad(S D=7.67)$ and $55.56 \quad(S D=9.82)$. Diagnostic and demographic variables across treatment are illustrated in Table 1.

\section{PUT TABLE 1 ABOUT HERE}

\section{Psychotherapy}

The data used in this study was treatment session 3 of psychotherapy, transcribed verbatim from audio recordings. Treatment consisted of 16 weekly, 60 minute sessions (that is, one session per week) of a specific manualised time-limited version of psychotherapy (Luborsky, 1984; Luborsky et al., 1995), which has received empirical support (Crits-Christoph et al., 2001). This psychotherapy is a well-known, time-limited, relationship-oriented therapy and forms part of the evidence base for dynamic therapies (Leichsenring, 2001; Leichsenring, Rabung, \& Leibing, 2004). The treatment was provided at a university health service clinic by ten doctoral-level 
clinical psychologists with comprehensive training in this psychotherapy applied to depression and personality disorders. A $\mathrm{PhD}$ clinical psychologist author with an extensive background in short-term dynamic psychotherapy provided weekly supervision to each therapist and monitored adherence using audiotapes and rating scales. There were no differences between therapists on adherence or competence ratings or in the way treatments were delivered across this study.

\section{Measures}

\section{The Therapeutic Cycles Model}

A microanalysis of a session transcript using the TCM (Mergenthaler, 1996) calculates the absolute and relative frequencies of each linguistic variable for therapist, patient and their combined language within blocks of 150 words throughout the session. As previously indicated, measured linguistic variables include emotional tone, the positive and negative valence of emotional tone, abstraction, and narrative style (Mergenthaler, 2008). From this data the emotionabstraction pattern of each word block (reflecting, relaxing, experiencing or connecting), as well as the presence of connecting cycles and emotional tone shift events, are determined.

\section{Procedure}

\section{Data analysis}

Sessions were transcribed from audio recordings according to the detailed rules and recommendations for transcribing psychotherapy samples of Mergenthaler and Stinson (1992). The Cycles Model software (Mergenthaler, 1996) was then used at the University of Ulm to perform a microanalysis of the 20 transcripts, reporting quantitative scores of the linguistic variables in each 150-word block for statistical assessment. 
Although samples were equivalent in severity at intake and session 3, as seen in Table 1, to be cautious we ran initial ANCOVA analyses controlling for intake BDI. This revealed that BDI at intake was not significantly related to the language variables measured in session 3 . As there was no relationship between initial severity and our findings, and given that the assumptions of normality were not met, for the results reported here we have chosen to only report nonparametric statistics.

To test group differences on the TCM variables sequentially across the session, each 60 minute session was split into 3 segments of time: 0-20 minutes, 21-40 minutes, and 41-60 minutes. TCM data indicating emotion-abstraction patterns, connecting cycles and emotional tone shift events in each 150-word block were converted to proportions of total word blocks within a session segment to control for length of transcript (Mergenthaler, 1996). This TCM data was then analysed with the non-parametric Mann-Whitney U test at the three time points, and from three perspectives: therapist language scores, patient language scores, and combined therapist-patient language scores (therapist-patient dyads). Exact significance will be reported due to small sample size. In order to examine the in-session processes of both most and least improved patients individually, comparisons within outcome groups of TCM data between session segments were examined using the Friedman two-way ANOVA and the Conover nonparametric method of multiple comparisons (Conover, 1980).

To test group differences in TCM variables in the entirety of the session, TCM data indicating emotion-abstraction patterns and connecting cycles in each 150-word block were converted to proportions of total word blocks to control for transcript length. Levels of emotional tone, abstraction and narrative style were analysed as relative frequencies of words spoken per 150word block. Comparisons between outcome groups on TCM data were done using Mann- 
Whitney U tests from two perspectives: therapist language scores and patient language scores. Exact significance will be reported due to small sample size. Cohen's d was used to measure all effect sizes. It should be noted that where proportions of session time were analysed, effect sizes are expected to be larger due to small sample size $(N=20)$.

\section{Results}

\section{Group differences in the temporal sequence of TCM variables}

\section{0-20 minutes of session}

As illustrated in Figure 1, combined therapist-patient data showed that the most improved group at 12-month follow-up spent a significantly greater proportion of time during 0-20 minutes of session 3 in connecting cycles $(M=43.10 \%, S D=24.07 \%, n=10)$ than did the least improved group $(M=18.70 \%, S D=7.36 \%, n=10), U=17.50, p=.011, d=1.48$. No other differences between outcome groups on emotion-abstraction patterns or shift events reached significance.

\section{1-40 minutes of session}

Most improved patients spent a significantly greater proportion of time in connecting word blocks during 21-40 minutes of session $3(M=16.67 \%, S D=7.16 \%, n=10)$ than did least improved patients $(M=9.15 \%, S D=7.42 \%, n=10), U=23.50, p=.043, d=1.03$. Further, as seen in Figure 1 , combined therapist-patient data showed that the most improved group spent a significantly greater proportion of time during 21-40 minutes of session 3 in connecting cycles $(M=48.08 \%$, $S D=26.01 \%, n=10)$ than did the least improved group $(M=22.39 \%, S D=20.76 \%, n=10), U=22.00$, $p=.035, d=1.09$. No other differences between outcome groups on emotion-abstraction patterns or shift events reached significance.

41-60 minutes of session 
Combined therapist-patient data showed that the most improved group spent a significantly greater proportion of time in relaxing word blocks during 41-60 minutes of session 3 $(M=32.80 \%, S D=6.75 \%, n=10)$ than did the least improved group $(M=17.26 \%, S D=10.30 \%$, $n=10), U=15.00, p=.007, d=1.78$. Further, combined therapist-patient data showed that the most improved group spent a significantly lesser proportion of time during 41-60 minutes of session 3 in connecting cycles $(M=20.80 \%, S D=11.18 \%, n=10)$ than did the least improved group $(M=55.34 \%, S D=26.32 \%, n=10), U=9.00, p=.001, d=1.71$. No other differences between outcome groups on emotion-abstraction patterns or shift events reached significance.

\section{PUT FIGURE 1 ABOUT HERE}

\section{Within group temporal sequence of TCM variables}

\section{Sessions of most improved patients}

Most improved patients significantly differed across session 3 in the proportion of time they spent in the relaxing pattern $\chi_{\mathrm{F}}^{2}=9.14 d f=2, n=10, p=.01$. Most improved patients spent a significantly lesser proportion of time in the relaxing pattern during 0-20 minutes of session 3 $(M=30.53 \%, S D=9.41 \%, n=10)$ than they did during $41-60$ minutes of session $3(M=41.31 \%$, $S D=7.24, n=10$ ), Mean Rank Difference $=1.30>$ Critical Rank Difference $=.70, d=1.28$. No other significant differences were found across the session for any other TCM variable.

\section{Sessions of least improved patients}

Therapists' dialogue with least improved patients significantly differed across session 3 in their proportion of shift events $\chi_{\mathrm{F}}^{2}=6.34 d f=2, n=10, p=.042$. Therapists' dialogue with least improved patients had a significantly lesser proportion of shift events during 0-20 minutes of 
session $3(M=1.85 \%, S D=4.56 \%, n=10)$ than it did during $41-60$ minutes $(M=6.90 \%, S D=5.67 \%$, $n=10$ ), Mean Rank Difference=1.05 > Critical Rank Difference=.77, $d=.98$.

Combined therapist-patient data showed that the least improved group significantly differed across session 3 in the proportion of time spent in connecting cycles $\chi_{\mathrm{F}}^{2}=9.90 d f=2, n=10$, $p=.007$. Combined therapist-patient data further showed that the least improved group spent a significantly lesser proportion of time in connecting cycles during 0-20 minutes of session 3 ( $M=$ 15.19\%, $S D=11.52 \%, n=10)$ than during $41-60$ minutes $(M=55.34 \%, S D=26.32 \%, n=10)$, Mean Rank Difference=1.15 > Critical Rank Difference=.69, $d=1.98$, and during 21-40 minutes of session $3(M=22.39 \%, S D=20.76 \%, n=10)$ than they did during 41-60 minutes, Mean Rank Difference $=1.25>$ Critical Rank Difference=.69, $d=1.39$. No other significant differences were found across the session for any other TCM variable.

\section{Group differences on TCM variables}

As seen in Table 2, when testing group differences on the TCM variables in the entirety of session 3, it was found that therapists' dialogue with most improved patients had a significantly higher proportion of positive emotional tone words and a significantly lower proportion of negative emotional tone words than their dialogue with least improved patients. Therapists' dialogue with most improved patients also had a significantly higher proportion of narrative marker words than did their dialogue with least improved patients (see Table 2). No other significant differences were found between therapists speaking with most and least improved patients in terms of emotion-abstraction patterns, abstraction or narrative style.

It was found that most improved patients completed significantly more connecting cycles than least improved patients. Most improved patients also spoke a significantly higher proportion of 
positive emotional tone words than least improved patients (see Table 2). No other differences between outcome groups on emotion-abstraction patterns, abstraction levels or narrative style reached significance.

PUT TABLE 2 ABOUT HERE

\section{Discussion}

Outcomes at 12-month follow-up for patients obtaining psychotherapy for depression and personality disorder could be accounted for by therapist-patient emotional and cognitive dialogue throughout the third session. During 0-20 minutes and 21-40 minutes of session 3 therapistpatient dyads most improved at 12-month follow-up spent more time in connecting cycles, that is, connecting emotion and cognition in a problem solving process. The strength of these findings are underscored by large effect sizes, $d=1.48$ and $d=1.09$ respectively, which reinforces that such differences in the dialogue were obvious and prominent, and of clinical as well as statistical significance. Therapist-patient dyads that were least improved spent more time in these connecting cycles during 41-60 minutes of session, whilst those most improved moved into a relaxing phase. Therapist dialogue with most improved patients was significantly higher in positive emotional tone and narrative words, and significantly lower in negative emotional tone words. The findings suggest that the timing of therapist-patient dialogue throughout session, and patient engagement with therapist interventions may be important.

Analysis of TCM variables at time segments throughout the session, revealed some of the therapist and patient contributions during the hour, based on patient outcome. 
Therapists and most improved patients spent a greater proportion of time in connecting cycles than did those least improved at the beginning of session 3. Connecting cycles indicate where emotional tone is connected with abstraction within the session, that is, where problems can be worked through both emotionally and cognitively. Positive emotion has been consistently linked to the cognitive problem solving process (Isen, et al., 1987; Links, et al., 2003). The TCM literature indicates that negative emotion occurs first within a session in order for problems to be elicited (deepen-and-provide), and is followed by an increase in positive emotion for problem solving processes to begin (broaden-and-build) (Mergenthaler, 2008). The present study indicates that most improved patients were able to move into a problem solving phase more quickly than least improved, marked by their higher number of connecting cycles early in session. This is consistent with our finding that therapists and most improved patients had higher levels of positive emotional tone throughout the entire session, and that patients did not differ between groups in their levels of negative emotional tone. This indicates that both groups were initiating problems to be discussed, but that most improved patients were engaging in more ongoing positive problem solving processes. The finding that most improved patients moved more quickly into this problem-solving process may also be due to these patients finding it easier to engage with their therapist, or being more comfortable within the therapy process, which serves to emphasise the importance of the therapist techniques, and may impact on the way the patient and therapist converse (Ackerman \& Hilsenroth, 2003; Orlinsky, et al., 1994).

Dialogue within a connecting cycle can be seen in an example from a transcript of a most improved patient: P: “...so hearing as we talk I sound very positive but I think I’ve got to put my thoughts into actions.” T: “And so what's different between what you're telling me and how you really feel inside?” P: “It's like there are two voices- I want to go to tech and learn anything else 
exciting, but I'm telling myself that 'you're not going.' Because I've got such low confidence in myself I tell myself I can't do something that I know I've started and I know I do ... I can.” Here we can see that the patient has insight into their own processes- their thoughts and actions within and outside of the session, and shows that they can connect their ambivalence with their selfunderstanding that they have the competence to complete difficult things. The therapist attempts to highlight the difference between where the patient is, and where they would like to be, by asking about emotion ('feel inside'). The patient responds with further insight into the connection between their thoughts and feelings. This passage demonstrates key features of the connecting cycle- patient and therapist insight into cognition and emotion in order to work through, or take action to problem solve, or "broaden and build" in some way. Therapist encouragement of positive emotional tone within session can be seen in an example from the transcript of one of the most improved patients: P: “...it’s obvious. Which is really sad because as I said, she hasn’t done anything...I’m often trying not to think about it...” T: “...it’s not pleasant to think about it obviously..." Here, the patient's word 'sad' is transformed by the therapist into 'pleasant', in an empathic yet positive connection to the difficult emotion. Further, the therapist uses a negation ('it's not pleasant') along with the positive term ('pleasant,') to uphold semantic meaning of what the patient has said. This subtle process suggests that the therapist may be encouraging the patient to shift into a positive problem solving process (Mergenthaler, 2008). Consistent with the findings of this study, therapist facilitation of the emotional expression of the patient has been found to be associated with improvement in psychodynamic psychotherapy (Diener, Hilsenroth, \& Weinberger, 2007). Further, Town et al. (2012) found that at the level of psychotherapy processes, therapist intervention had significant impacts on immediate emotional arousal in the patient. Specifically, Carryer and Greenberg (2010) found that it is a moderate amount of 
expressed emotional arousal that is most helpful in therapy for depression, rather than a high or low amount of emotion. Particularly consistent with the results of the present study were findings by Missirlian, Toukmanian, Warwar and Greenberg (2005) that integration is what is important emotional arousal in conjunction with information and perceptual processing was more predictive of positive outcome than either of these variables alone.

21-40 minutes of session

Most improved patients spent a greater proportion of time in the connecting pattern than did least improved in the middle of session 3. Therapists and most improved patients spent more time in connecting cycles than did those least improved. This indicates that most improved patients continued, up to the $40^{\text {th }}$ minute of therapy, to activate and solve problems with their therapist by frequently connecting emotion and cognition. The finding that therapists of patients in this group had high levels of narrative words throughout the session suggests that therapists may have supported the continual activation of problems to be worked on in session, thus focussing on behavioural regulation.

41-60 minutes of session

Towards the end of the session, therapists and most improved patients spent less time in connecting cycles, and a greater amount of time relaxing than did those least improved. Therapists and most improved patients also spent more time relaxing during 41-60 minutes of session than they themselves did during 0-20 minutes. Relaxing is a period of descriptive language, where both emotional tone and abstraction is low. Conversation is typically not directly related to central issues, allowing regeneration (Mergenthaler, 2008). These findings indicate that critical work has not been done by the most improved patients in this late stage of the session, rather a period of recouping has occurred. 
Therapists and least improved patients spent more time during the end 41-60 minutes of session in connecting cycles than did those most improved. Therapists and least improved patients also spent more time in connecting cycles at the end of session than they themselves did during 0-20 minutes or 21-40 minutes of session. This suggests that it took least improved patients 40 minutes before increasing problem solving via connecting emotion and cognition. In this last 41-60 minutes of session, therapist dialogue with least improved patients also had more emotional tone shift events than in the first 0-20 minutes. Shift events are a change to positive emotional tone to encourage connecting. This indicates that therapists may have worked hard with the least improved patients at the end of session to encourage positive emotion and problem solving, consistent with the literature highlighting the importance of emotional processing and the therapist's role in facilitating this (Town, et al., 2012). This late activity for least improved patients and therapists may be due to therapists finding it more difficult to engage these patients in therapeutic work, or may be due to other patient and therapist variables, which may also impact on language variables (Ackerman \& Hilsenroth, 2003; Orlinsky, et al., 1994).

\section{Overall in session 3}

Most improved patients were found to pass significantly more connecting cycles over the entire session than did the least improved patients, consistent with previous research. As indicated, this is where emotion and cognition is connected in a positive way for problem solving to occur, and a "good therapy" will be marked by an increasing number of successfully completed connecting cycles (Mergenthaler, 2008). No significant differences were found in the number of shift events between the groups. This is interesting, as shift events to positive emotional tone have been associated with connecting and improvement in therapy. We may speculate that considering the finding that most improved patients and therapists had higher 
levels of positive emotional tone in their sessions, that after a shift event they were able to maintain positive emotion, whilst least improved may not have been. Alternatively, perhaps it is the quality of shift events, in terms of material covered that relates to mastery of deeper dynamic conflicts (Grenyer \& Luborsky, 1996), rather than the number of shift events, that is important. This warrants further research. Further, abstraction levels did not significantly differ between outcome groups. It could be hypothesized that to promote change in this sample, it was necessary for therapists to regulate the valence of emotional tone rather than increase reflecting and intellectualisation. This may be due to the diagnostic characteristics of the sample, or of the style of the therapists or therapy used in the study. Further research into patterns of cognitiveemotional processing in samples with specific diagnostic categories is needed. The finding of no group differences in the experiencing pattern (where emotion is high and abstraction low) should be noted, considering that emotional language itself was found to be important. Rather, times where high emotion coincided with cognitive language (connecting cycles) were found to be relevant to outcome. These findings are not only consistent with the TCM literature, but with literature on emotional processing in psychotherapy. Greenberg and Pascual-Leone (2006) suggest that neither emotional arousal alone nor reflection alone is sufficient for emotional processing, with studies suggesting that both are required for therapeutic change (Stalikas \& Fitzpatrick, 1995; Watson, 1996).

There were several strengths and limitations within this study. As expected, analysing the patient and therapist data separately was valuable in drawing conclusions about the role of both speakers in therapy, and builds on previous research. A previous study investigating TCM variables between early and late sessions within a therapy, found no significant differences in combined patient-therapist language during early therapy sessions, but higher emotion and 
abstraction for successful patients during sessions late in therapy (Mergenthaler, 1996). It was concluded that a learning process was occurring across the therapy. However, the current study seems to build on these findings, through separating patient and therapist speech. This present study was able to show not only some therapist contributions towards improvement within a single session, but also that some of the processes towards improvement in therapy began at an early stage. Further, this study is the first to investigate the sequence of language use across an early session, in relation to long-term outcome. Limitations include the small and select sample utilised in this study. This may have limited the power of some analyses and increased the likelihood of spurious results. Replication would allow further understanding with regards to the stability of these findings across different samples and conditions. However, this sample size is consistent with research in this field (Lepper \& Mergenthaler, 2005, 2007, 2008), and is due to the time consuming nature of this kind of research given the magnitude of data to be managed and the larger pool required to be collected in order to allow a careful demographic matching procedure supporting the otherwise equivalence between samples. It should be noted that the conclusions drawn from this study are limited by the diagnostic criteria used to select the sample. Further, therapists in this sample spoke far less words within session than did patients. This made our aim of investigating therapist language alongside patient more difficult. As this data includes sequential in-session treatment events, possible interdependency between observations should be considered when interpreting the results. The results of this study are further limited to analyses of a single therapeutic hour per patient. Although this fulfilled our aim to investigate processes within an early session, it is noted that a different pattern of results may be found in other sessions. Although the BDI scores at session 3 were not statistically different, it is possible that changes occurring both prior to this session, and throughout the entire course of the therapy, are 
also likely to impact on long-term outcome and further studies are needed to search further into these intriguing findings.

Therapists were able to use more positive emotional tone throughout sessions with most improved patients. This may have enabled a problem solving process and thus more linguistic markers, particularly in the first 40 minutes of session. We may hypothesize that therapists found it more difficult to engage least improved patients in therapeutic work. Least improved patients appeared to struggle to move from problem activation (deepen-and-provide) to the problem solving process (broaden-and-build), and their therapists seemed to work hard to initiate this process at the end of session. It seems that work done during the first 40 minutes of session is most valuable. These results provide a first step towards characterising the interior nature and sequence of psychotherapy sessions via the emotional-cognitive language used. Future research into therapeutic processes across the session would be valuable. Should further research replicate these findings of the importance of specific patterns of therapist-patient dialogue, this could have profound implications for how clinical psychotherapy treatments are manualised, and provide specific guidance for desirable therapist and patient behaviours through the therapy hour. 


\section{References}

Ablon, J. S., Levy, R. A., \& Katzenstein, T. (2006). Beyond brand names of psychotherapy: Identifying empirically supported change processes. Psychotherapy, 43(2), 216-231. doi: 10.1037/0033-3204.43.2.216

Ackerman, S. J., \& Hilsenroth, M. J. (2003). A review of therapist characteristics and techniques positively impacting the therapeutic alliance. Clinical Psychology Review, 23, 1-33. doi: 10.1016/S0272-7358(02)00146-0

Agresti, A. (1992). A survey of exact inference for contingency tables. Statistical Science, 7(1), 131-177. doi: 10.1214/ss/1177011454

American Psychiatric Association. (1994). Diagnostic and statistical manual of mental disorders (4th ed.). Washington, DC.: American Psychiatric Association.

Baldwin, S. A., Wampold, B. E., \& Imel, Z. E. (2007). Untangling the alliance-outcome correlation: Exploring the relative importance of therapist and patient variability in the alliance. Journal of Consulting and Clinical Psychology, 75, 842-852, . doi: 10.1037/0022-006X.75.6.842

Beck, A. T., Steer, R. A., \& Garbin, M. G. (1988). Psychometric properties of the Beck Depression Inventory: Twenty-five years of evaluation. Clinical Psychology Review, 8, 77-100. doi: 10.1016/0272-7358(88)90050-5 
Beck, A. T., Ward, C. H., Mendelson, M., Mock, J. E., \& Erbaugh, J. K. (1961). An inventory for measuring depression. Archives of General Psychiatry, 4, 561-571.

Benelli, E., Mergenthaler, E., Walter, S., Messina, I., Sambin, M., Buchheim, A., et al. (2012). Emotional and cognitive processing of narratives and individual appraisal styles: recruitment of cognitive control networks vs. modulation of deactivations. Frontiers in Human Neuroscience, 6(239). doi: 10.3389/fnhum.2012.00239

Blatt, S. J., Sanislow, C. A., Zuroff, D. C., \& Pilkonis, P. A. (1996). Characteristics of effective therapists: Further analyses of data from the National Institute of Mental Health treatment of depression collaborative research program. Journal of Consulting and Clinical Psychology, 64(6), 1276-1284. doi: 10.1037/0022-006X.64.6.1276

Bourke, M. E., \& Grenyer, B. F. S. (2010). Psychotherapists' response to borderline personality disorder: A core conflictual relationship theme analysis. Psychotherapy Research, 20(6), 680-691. doi: 10.1080/10503307.2010.504242

Bromet, E., Andrade, L. H., Hwang, I., Sampson, N. A., Alonso, J., de Girolamo, G., et al. (2011). Cross-national epidemiology of DSM-IV major depressive episode. BCM Medicine, 9(90). doi: 10.1186/1741-7015-9-90

Buchheim, A., \& Mergenthaler, E. (2000). The relationship among attachment representation, emotion-abstraction patterns and narrative style: A computer-based text analysis of the Adult Attachment Interview. Psychotherapy Research, 10(4), 390-407. doi: 10.1093/ptr/10.4.390 
Buchheim, A., Viviani, R., Kessler, H., Kächele, H., Cierpka, M., Roth, G., et al. (2012). Changes in prefrontal-limbic function in major depression after 15 months of long-term psychotherapy. PLoS ONE, 7(3), e33745. doi: 10.1371/journal.pone.0033745

Carryer, J. R., \& Greenberg, L. S. (2010). Optimal levels of emotional arousal in experiential therapy of depression. Journal of Consulting and Clinical Psychology, 78(2), 190-199. doi: $10.1037 / \mathrm{a} 0018401$

Cohen, S. D., Norris, L., Acquaviva, K., Peterson, R. A., \& Kimmel, P. L. (2007). Screening, diagnosis, and treatment of depression in patients with end-stage renal disease. Clinical Journal of American Society of Nephrology, 2, 1332-1342. doi: 10.2215/CJN.03951106

Comninos, A., \& Grenyer, B. F. S. (2007). The influence of interpersonal factors on the speed of recovery from major depression. Psychotherapy Research, 17, 239-249. doi: $10.1080 / 10503300600849140$

Conover, W. J. (1980). Practical nonparametric statistics (2nd ed.). Canada: John Wiley \& Sons Inc.

Crits-Christoph, P., Connolly, M. B., Gallop, R., Barber, J. P., Tu, X., Gladis, M., et al. (2001). Early improvement during manual-guided cognitive and dynamic psychotherapies predicts 16-week remission status Journal of Psychotherapy Practice and Research, 10, $145-154$.

Del Re, A. C., Flückiger, C., Horvath, A. O., Symonds, D., \& Wampold, B. E. (2012). Therapist effects in the therapeutic alliance-outcome relationship: A restricted-maximum 
likelihood meta-analysis. Clinical Psychology Review, 32, 642-649. doi: 10.1016/j.cpr.2012.07.002

Diener, M. J., Hilsenroth, M. J., \& Weinberger, J. (2007). Therapist affect focus and patient outcomes in psychodynamic psychotherapy: A meta-analysis. American Journal of Psychiatry, 164, 936-941.

Dinger, U., Strack, M., Leichsenring, F., Wilmers, F., \& Schauenburg, H. (2008). Therapist effects on outcome and alliance in inpatient psychotherapy. Journal of Clinical Psychology, 64, 344-354. doi: 10.1002/jclp. 20443

Elliott, R. (2010). Psychotherapy change process research: Realizing the promise. Psychotherapy Research, 20(2), 123-135. doi: 10.1080/10503300903470743

Fennell, M. J., \& Teasdale, J. D. (1987). Cognitive therapy for depression: Individual differences and the process of change. Cognitive Therapy and Research, 11, 253-271. doi: 10.1007/BF01183269

First, M. B., Gibbon, M., Spitzer, R. L., Williams, J. B. W., \& Benjamin, L. S. (1997). Structured clinical interview for DSM-IV Axis II personality disorders, (SCID-II). Washington, D.C.: American Psychiatric Press.

First, M. B., Spitzer, R. L., Gibbon, M., \& Williams, J. B. W. (1996). Structured clinical interview for DSM-IV Axis I disorders. Washington, D.C.: American Psychiatric Press. 
Frederickson, B. L. (1998). What good are positive emotions? Review of General Psychiatry, 2(3), 300-319. doi: 10.1037/1089-2680.2.3.300

Frederickson, B. L. (2001). The role of positive emotions in positive psychology: The broadenand-build theory of positive emotions. American Psychologist, 56(3), 218-226. doi: 10.1037/0003-066X.56.3.218

Gelo, O. C. G., \& Mergenthaler, E. (2012). Unconventional metaphors and emotional-cognitive regulation in a metacognitive interpersonal therapy. Psychotherapy Research, 22(2), 159175. doi: 10.1080/10503307.2011.629636

Gilboa-Schechtman, E., \& Shahar, G. (2006). The sooner, the better: Temporal patterns in brief treatment of depression and their role in long-term outcome. Psychotherapy Research, 16(3), 374-384. doi: 10.1080/10503300500485425

Goldapple, K., Segal, Z., Garson, C., Lau, M., Bieling, P., Kennedy, S., et al. (2004). Modulation of cortical-limbic pathways in major depression. Archives of General Psychiatry, 61, 3441. doi: 10.1001/archpsyc.61.1.34

Greenberg, L. S., \& Pascual-Leone, A. (2006). Emotion in psychotherapy: A practice-friendly research review. Journal of Clinical Psychology, 62(5), 611-630. doi: 10.1002/jclp.20252

Grenyer, B. F. S., \& Luborsky, L. (1996). Dynamic change in psychotherapy: Mastery of interpersonal conflicts. Journal of Consulting and Clinical Psychology, 64, 411-416. 
Henry, W. P., Schacht, T. E., \& Strupp, H. H. (1990). Patient and therapist introject, interpersonal process, and differential psychotherapy outcome. Journal of Consulting and Clinical Psychology, 58(6), 768-774. doi: 10.1037/0022-006X.58.6.768

Hollon, S. D., Thase, M. E., \& Markowitz, J. C. (2002). Treatment and prevention of depression. Psychological Science in the Public Interest, 3(2), 39-77. doi: 10.1111/1529-1006.00008

Hölzer, M., Pokorny, D., Kächele, H., \& Luborsky, L. (1997). The verbalization of emotions in the therapeutic dialogue- A correlate of therapeutic outcome? Psychotherapy Research, 7(3), 261-273. doi: 10.1080/10503309712331332013

Horvath, A. O., Del Re, A. C., Flückiger, C., \& Symonds, D. (2011). Alliance in individual psychotherapy. Psychotherapy, 48(1), 9-16. doi: 10.1037/a0022186

Isen, A. M., Daubman, K. A., \& Nowicki, G. (1987). Positive affect facilitates creative problem solving. Journal of Personality and Social Psychology, 52(6), 1122-1131. doi: 10.1037/0022-3514.52.6.1122

Kendall, P. C., Hollon, S. D., Beck, A. T., Hammen, C. L., \& Ingram, R. E. (1987). Issues and recommendations regarding use of the Beck Depression Inventory. Cognitive Therapy and Research, 11(3), 289-299. doi: 10.1007/BF01186280

Kessler, R. C., Berglund, P., Demler, O., Jin, R., Merikangas, K. R., \& Walters, E. E. (2005). Lifetime prevalence and age-of-onset distributions of DSM-IV disorders in the National Comorbidity Survey Replication. Archives of General Psychiatry, 62(6), 593-602. 
Lambert, M. (2007). What we have learned from a decade of research aimed at improving psychotherapy outcome in routine care. Psychotherapy Research, 17(1), 1-14. doi: 10.1080/10503300601032506

Leichsenring, F. (2001). Comparative effects of short-term psychodynamic psychotherapy and cognitive-behavioral therapy in depression: A meta-analytic approach. Clinical Psychology Review, 21(3), 401-419. doi: 10.1016/S0272-7358(99)00057-4

Leichsenring, F., Leibing, E., Kruse, J., New, A., \& Leweke, F. (2011). Borderline Personality Disorder. Lancet, 377, 74-84. doi: 10.1016/S0140-6736(10)61422-5

Leichsenring, F., Rabung, S., \& Leibing, E. (2004). The efficacy of short-term psychodynamic psychotherapy in specific psychiatric disorders: A meta-analysis. Archives of General Psychiatry, 61, 1208-1216. doi: 10.1001/archpsyc.61.12.1208

Lepper, G., \& Mergenthaler, E. (2005). Exploring group process. Psychotherapy Research, 15(4), 433-444. doi: 10.1080/10503300500091587

Lepper, G., \& Mergenthaler, E. (2007). Therapeutic Collaboration: How does it work? Psychotherapy Research, 17(5), 576-587. doi: 10.1080/10503300601140002

Lepper, G., \& Mergenthaler, E. (2008). Observing therapeutic interaction in the "Lisa” case. Psychotherapy Research, 18(6), 634-644. doi: 10.1080/10503300701442001

Levenson, J. C., Wallace, M. L., Fournier, J. C., Rucci, P., \& Frank, E. (2012). The role of personality pathology in depression treatment outcome with psychotherapy and 
pharmacotherapy. Journal of Consulting and Clinical Psychology, 80(5), 719-729. doi: 10.1037/a0029396

Levitt, H. M., \& Piazza-Bonin, E. (2011). Therapists' and clients' significant experiences underlying psychotherapy discourse. Psychotherapy Research, 21(1), 70-85. doi: 10.1080/10503307.2010.518634

Lin, E. H. B., Katon, W. J., VonKorff, M., Russo, J. E., Simon, G. E., Bush, T. M., et al. (1998). Relapse of depression in primary care: Rate and clinical predictors. Archives of Family Medicine, 7(5), 443-449.

Linden, D. E. J. (2006). How psychotherapy changes the brain- The contribution of functional neuroimaging. Molecular Psychiatry, 11, 528-538. doi: 10.1038/sj.mp.4001816

Links, P. S., Bergmans, Y., \& Cook, M. (2003). Psychotherapeutic interventions to prevent repeated suicidal behavior. Brief Treatment and Crisis Intervention, 3(4), 445-464. doi: 10.1093/brief-treatment/mhg033

Luborsky, L. (1984). Principles of psychoanalytic psychotherapy. New York: Basic Books.

Luborsky, L., Mark, D., Hole, A. V., Popp, C., Goldsmith, B., \& Cacciola, J. (1995). Supportiveexpressive dynamic psychotherapy for depression: A time-limited version. In J. P. Barber \& P. Crits-Christoph (Eds.), Dynamic therapies for psychiatric disorders: Axis I (pp. 1342). New York: Basic Books. 
Luborsky, L., McLellan, T., Woody, G. E., O’Brien, C. P., \& Auerbach, A. (1985). Therapist success and its determinants. Archives of General Psychiatry, 42, 602-611.

Luborsky, L., Singer, B., \& Luborsky, L. (1975). Comparative studies of psychotherapies: Is it true that “everyone has won and all must have prizes?”. Archives of General Psychiatry, 32, 995-1008.

Matthey, S., Barnett, B., Ungerer, J., \& Waters, B. (2000). Paternal and maternal depressed mood during the transition to parenthood. Journal of Affective Disorders, 60, 75-85. doi: 10.1016/S0165-0327(99)00159-7

McCarthy, K. L., Mergenthaler, E., Schneider, S., \& Grenyer, B. F. S. (2011). Psychodynamic change in psychotherapy: Cycles of patient-therapist linguistic interactions and interventions. Psychotherapy Research, 21(6), 722-731. doi: 10.1080/10503307.2011.615070

Mergenthaler, E. (1996). Emotion-abstraction patterns in verbatim protocols: A new way of describing psychotherapeutic processes. Journal of Consulting and Clinical Psychology, 64(6), 1306-1315. doi: 10.1037/0022-006X.64.6.1306

Mergenthaler, E. (2008). Resonating minds: A school-independent theoretical conception and its empirical application to psychotherapeutic processes. Psychotherapy Research, 18(2), 109-126. doi: 10.1080/10503300701883741 
Mergenthaler, E., \& Bucci, W. (1999). Linking verbal and non-verbal representations: Computer analysis of referential activity. British Journal of Medical Psychology, 72, 339-354. doi: $10.1348 / 000711299160040$

Mergenthaler, E., \& Stinson, C. (1992). Psychotherapy transcription standards. Psychotherapy Research, 2(2), 125-142. doi: 10.1080/10503309212331332904

Missirlian, T. M., Toukmanian, S. G., Warwar, S. H., \& Greenberg, L. S. (2005). Emotional arousal, client perceptual processing, and the working alliance in experiential psychotherapy for depression. Journal of Consulting and Clinical Psychology, 73(5), 861-871. doi: 10.1037/0022-006X.73.5.861

National Institute for Health and Clinical Excellence. (2009a). Borderline personality disorder: Treatment and management. London: National Institute for Health and Clinical Excellence.

National Institute for Health and Clinical Excellence. (2009b). Depression: The treatment and management of depression in adults. London: National Institute for Health and Clinical Excellence.

Newton-Howes, G., Tyrer, P., \& Johnson, T. (2006). Personality disorder and the outcome of depression: meta-analysis of published studies. The British Journal of Psychiatry, 188, 13-20. doi: 10.1192/bjp.188.1.13

Norcross, J. C., \& Wampold, B. E. (2011). Evidence-based therapy relationships: Research conclusions and clinical practices. Psychotherapy, 48(1), 98-102. doi: 10.1037/a0022161 
Orlinsky, D. E., Grawe, K., \& Parks, B. K. (1994). Process and outcome in psychotherapy. In A. E. Bergin \& S. L. Garfield (Eds.), Handbook of psychotherapy and behavior change (4th ed., pp. 270-378). New York: Wiley.

Pennebaker, J. W., Mehl, M. R., \& Niederhoffer, K. G. (2003). Psychological aspects of natural language use: Our words, our selves. Annual Review of Psychology, 54, 547-577. doi: 10.1146/annurev.psych.54.101601.145041

Pinto, A., \& Francis, G. (1993). Cognitive correlates of depressive symptoms in hospitalised adolescents. Adolescence, 28, 661-672.

Skodol, A. E., Grilo, C., Keyes, K. M., Geier, T., Grant, B. F., \& Hasin, D. S. (2011). Relationship of personality disorders to the course of major depressive disorder in a nationally representative sample. American Journal of Psychiatry, 168, 257-264. doi: 10.1176/appi.ajp.2010.10050695

Skodol, A. E., Gunderson, J. G., McGlashan, T. H., Dyck, I. R., Stout, R. L., Bender, D. S., et al. (2002). Functional impairment in patients with schizotypal, borderline, avoidant, or obsessive-compulsive personality disorder. American Journal of Psychiatry, 159, 276283. doi: 10.1176/appi.ajp.159.2.276

Stalikas, A., \& Fitzpatrick, M. (1995). Client good moments: An intensive analysis of a single session. Canadian Journal of Counselling, 29, 160-175. 
Startup, M., Jackson, M. C., \& Bendix, S. (2002). The concurrent validity of the global assessment of functioning (GAF). British Journal of Clinical Psychology, 41, 417-422. doi: 10.1348/014466502760387533

Taylor, E. B., \& Klein, D. N. (1989). Assessing recovery in depression: Validity of symptom inventories. Cognitive Therapy and Research, 13(1), 1-8. doi: 10.1007/BF01178485

Town, J. M., Hardy, G. E., McCullough, L., \& Stride, C. (2012). Patient affect experiencing following therapist interventions in short-term dynamic psychotherapy. Psychotherapy Research, 22(2), 208-219. doi: 10.1080/10503307.2011.637243

Valdés, N., Dagnino, P., Krause, M., Pérez, J. C., Altimir, C., Tomicic, A., et al. (2010). Analysis of verbalized emotions in the psychotherapeutic dialogue during change episodes. Psychotherapy Research, 20(2), 136-150. doi: 10.1080/10503300903170921

Villmann, T., Liebers, C., Bergmann, B., Gumz, A., \& Geyer, M. (2008). Investigation of psycho-physiological interactions between patient and therapist during a psychodynamic therapy and their relation to speech using in terms of entropy analysis using a neural network approach. New Ideas in Psychology, 26, 309-325. doi: 10.1016/j.newideapsych.2007.07.010

Walter, S., Schiepek, G. K., Schneider, S., Strunk, G., Kaimer, P., \& Mergenthaler, E. (2010). The synchronization of plan activations and emotion-abstraction patterns in the psychotherapeutic process: A single-case study. Psychotherapy Research, 20(2), 214223. doi: $10.1080 / 10503300903277437$ 
Wampold, B. E. (2000). Outcomes of individual counseling and psychotherapy: Empirical evidence addressing two fundamental questions. In S. D. Brown \& R. W. Lent (Eds.), Handbook of counseling psychology (4th ed., pp. 711-739). New York: Wiley.

Watson, J. C. (1996). The relationship between vivid description, emotional arousal, and insession resolution of problematic reactions. Journal of Consulting and Clinical Psychology, 64, 459-464. doi: 10.1037/0022-006X.64.3.459

Zanarini, M. C. (2009). Psychotherapy of borderline personality disorder. Acta Psychiatrica Scandinavica, 120, 373-377. 
Table 1

Comparison between Characteristics of Most Improved Patients and Least Improved Patients at 12-Month Follow-up $(N=20)$.

\begin{tabular}{lccccccccc}
\hline & \multicolumn{1}{c}{ Most Improved } & \multicolumn{1}{c}{ Least Improved } & & & \\
Variable & $\boldsymbol{n}$ & Mean & SD & $\boldsymbol{n}$ & Mean & SD & $\boldsymbol{t}$ & $\boldsymbol{d} \boldsymbol{f}$ & $\boldsymbol{p}$ \\
Intake BDI & 10 & 26.30 & 7.75 & 10 & 29.70 & 5.25 & -1.15 & 18 & .266 \\
Session 3 BDI & 10 & 21.63 & 9.55 & 10 & 28.50 & 12.06 & -1.26 & 14 & .227 \\
Termination BDI & 10 & 7.70 & 3.30 & 10 & 20.00 & 13.32 & -2.83 & 10 & .018 \\
Follow-up BDI & 10 & 6.40 & 4.38 & 10 & 21.88 & 4.34 & -7.73 & 17 & $<.000$ \\
Age & 10 & 41.9 & 12.22 & 10 & 43.4 & 13.70 & -.25 & 18 & .799 \\
Education in years & 10 & 13.00 & 2.05 & 10 & 13.8 & 2.53 & -.78 & 18 & .448 \\
& & $\mathbf{\%}$ & & & $\mathbf{\%}$ & & & & $\boldsymbol{p}^{\mathbf{a}}$ \\
Gender & & & & & & & & & \\
Male & 60 & $(6 / 10)$ & & 40 & $(4 / 10)$ & & & & .656 \\
Female & 40 & $(4 / 10)$ & & 60 & $(6 / 10)$ & & & & \\
In a current relationship & 60 & $(6 / 10)$ & & 70 & $(7 / 10)$ & & & & 1.000 \\
Currently employed & 60 & $(6 / 10)$ & & 60 & $(6 / 10)$ & & & & 1.000 \\
Chronic depression & 80 & $(8 / 10)$ & & 90 & $(9 / 10)$ & & & & 1.000 \\
\hline
\end{tabular}

Note. $\mathrm{BDI}=$ Beck Depression Inventory; Most Improved= 10 BDI scores $\leq 16$ at 12 -month follow-up; Least Improved= 10 BDI scores $>16$ at 12-month follow-up.

${ }^{\text {a }} p$ value is Fisher's Exact test (2-sided), as expected frequencies are low in a $2 \mathrm{x} 2$ design due to small sample size (Agresti, 1992). No statistic is reported with this test. 
Table 2

Comparison between Most Improved Patients and Least Improved Patients at 12-Month Followup on TCM variables in Session $3(N=20)$.

\begin{tabular}{|c|c|c|c|c|c|c|c|c|}
\hline \multirow[t]{2}{*}{ Linguistic Variable } & \multirow[t]{2}{*}{ Speaker } & \multicolumn{2}{|c|}{ Most Improved } & \multicolumn{5}{|c|}{ Least Improved } \\
\hline & & $n$ & $\mathbf{M}$ & $n$ & $\mathbf{M}$ & $\boldsymbol{U}$ & $p$ & $d$ \\
\hline Connecting cycle & $\mathrm{T}$ & 10 & $0.43 \%$ & 10 & $0.86 \%$ & 35.00 & .280 & .45 \\
\hline Emotional tone & $\mathrm{T}$ & 592 & $4.96 \%$ & 603 & $4.72 \%$ & 170263.00 & .160 & .04 \\
\hline Positive emotional tone & $\mathrm{T}$ & 592 & $3.30 \%$ & 603 & $2.74 \%$ & 160374.00 & $.001 *$ & .09 \\
\hline Negative emotional tone & $\mathrm{T}$ & 592 & $1.66 \%$ & 603 & $1.97 \%$ & 166410.00 & $.024 *$ & .09 \\
\hline Abstraction & $\mathrm{T}$ & 592 & $6.12 \%$ & 603 & $6.41 \%$ & 175914.00 & .662 & .04 \\
\hline Narrative style & $\mathrm{T}$ & 592 & $51.63 \%$ & 603 & $47.25 \%$ & 158329.00 & $.001^{*}$ & .18 \\
\hline Connecting cycle & $\mathrm{P}$ & 10 & $5.85 \%$ & 10 & $4.16 \%$ & 23.50 & $.043 *$ & .94 \\
\hline Emotional tone & $\mathrm{P}$ & 592 & $4.87 \%$ & 603 & $4.41 \%$ & 155410.00 & $<.001^{*}$ & .16 \\
\hline Positive emotional tone & $\mathrm{P}$ & 592 & $2.85 \%$ & 603 & $2.22 \%$ & 141354.00 & $<.001^{*}$ & .27 \\
\hline Negative emotional tone & $\mathrm{P}$ & 592 & $2.02 \%$ & 603 & $2.19 \%$ & 170760.00 & .194 & .10 \\
\hline Abstraction & $\mathrm{P}$ & 592 & $5.15 \%$ & 603 & $5.01 \%$ & 171745.50 & .258 & .05 \\
\hline Narrative style & $\mathrm{P}$ & 592 & $65.59 \%$ & 603 & $64.96 \%$ & 177460.50 & .863 & .07 \\
\hline
\end{tabular}


Figure 1. Between group differences in time spent in TCM patterns during three segments of session 3 (Combined therapist-patient data; $N=20$ ).

Most Improved $=10$ BDI scores $\leq 16$ at 12-month follow-up; Least Improved $=10$ BDI scores $>16$ at 12-month follow-up. Minutes 0-20: $\mathrm{b}=$ beginning, Minutes 21-40: $\mathrm{m}=$ middle, Minutes 41-60: $\mathrm{e}=$ end Rel $=$ relaxing, Ref $=$ reflecting, Exp $=$ experiencing, Conn $=$ connecting, Cycle $=$ connecting cycle, Shift = emotional tone shift event. Error bars represent standard error of the mean.

$* p<.05$. 


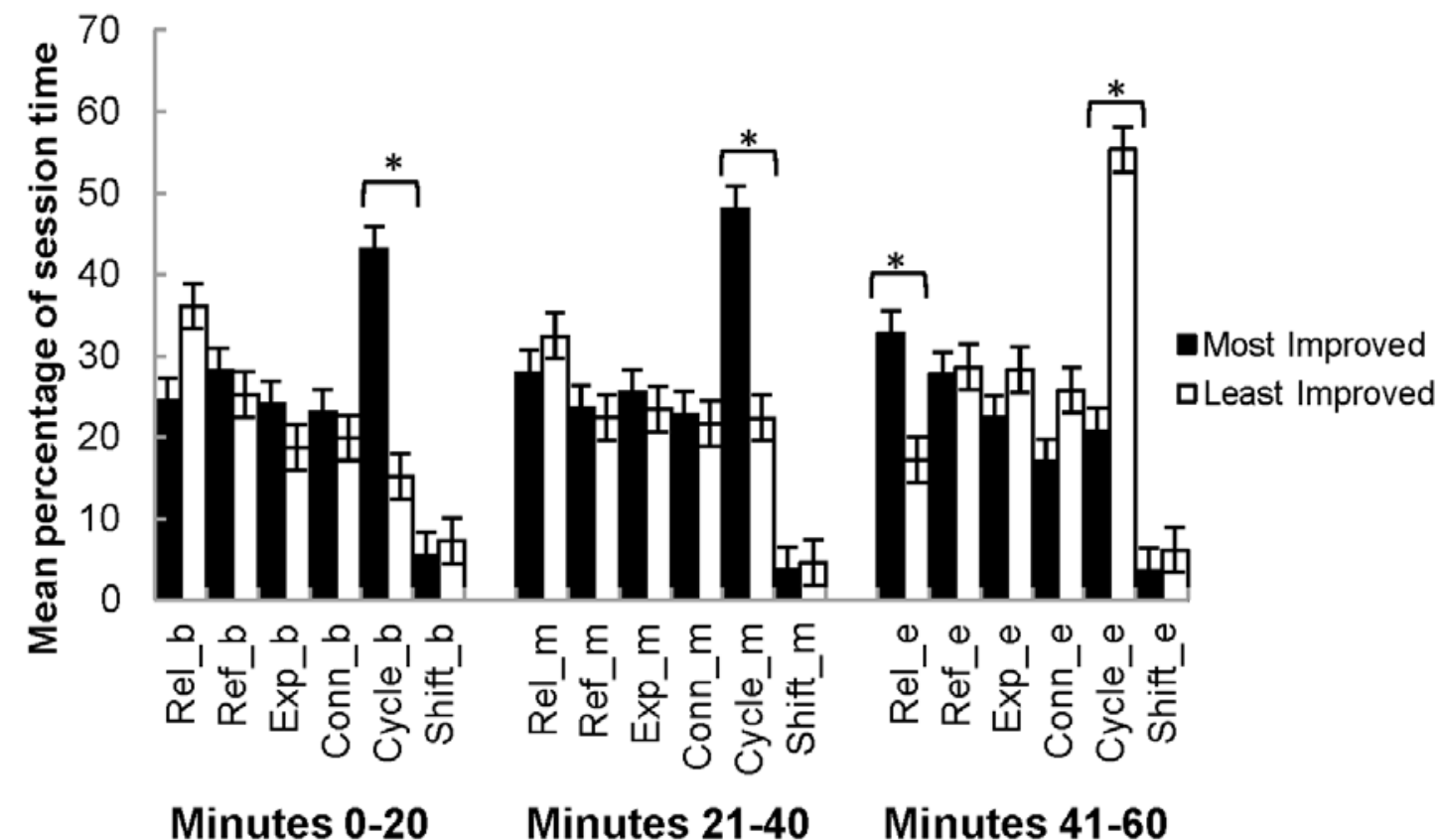

FIGURE 1 